\title{
ANALISIS RISIKO USAHATANI JAMUR MERANG DI KECAMATAN CILAMAYA KULON KABUPATEN KARAWANG
}

\author{
RISK ANALYSIS OF MUSHROOM FARMING IN CILAMAYA KULON \\ KARAWANG DISTRICT
}

\author{
Kiki Sasmita*, Abubakar, Luthfi Nur'azkiya \\ Program Studi Agribisnis Fakultas Pertanian Universitas Singaperbangsa Karawang \\ Jl. HS. Ronggo Waluyo, Puseurjaya, Kec. Telukjambe Timur, Kabupaten Karawang \\ *Email: kiki.sasmita7@gmail.com
}

(Diterima 15-12-2021; Disetujui 22-01-2022)

\begin{abstract}
ABSTRAK
Jamur merang merupakan salah satu komoditas sayuran unggulan yang banyak dibudidayakan di Kabupaten Karawang. Tujuan penelitian ini adalah untuk mengetahui: 1) risiko yang dihadapi petani jamur merang dan bagaimana risiko terhadap produksi, harga dan pendapatan 2) persepsi petani terhadap risiko di Kecamatan Cilamaya Kulon, 3) cara petani dalam menghadapi risiko. Metode yang digunakan adalah deskriptif analitik. Penelitian ini dilaksanakan di Kecamatan Cilamaya Kulon yang tersebar di Desa Pasirukem, Pasirjaya dan Muktijaya. Analisis data yang digunakan adalah analisis deksriptif untuk menggambarkan jenis-jenis risiko dan cara petani menghadapi risiko, analisis kuantitatif untuk mengukur risiko produksi, harga dan pendapat dengan menggunakan koefisien variasi, dan analisis persepsi petani yang diukur dengan menggunakan skala likert. Hasil penelitian diketahui bahwa jenis-jenis risiko yang dihadapi petani jamur merang di Kecamatan Cilamaya Kulon yaitu: risiko produksi yaitu kualitas bibit yang kurang bagus, risiko harga/pasar yaitu harga jual fluktuatif, risiko institusi yaitu tidak ada penyuluh pertanian, risiko manusia yaitu berkurangnya tenaga kerja, risiko keuangan yaitu modal yang dimiliki oleh petani sedikit. Petani memiliki persepsi yang baik terhadap risiko karena menganggap risiko yang terjadi tidak terlalu mengganggu. Cara petani dalam menghadapi risiko yaitu: Sebelum petani melakukan usahatani, petani membuat perencanaan bersama kelompok tani. Saat masa produksi petani melakukan pengaturan suhu didalam kumbung jamur agar suhu tetap terjaga. Setelah mengalami risiko petani tetap melanjutkan usahatani jamur merang dan mencari pekerjaan lain guna mendapatkan pendapatan tambahan.
\end{abstract}

Kata Kunci : jamur merang, persepsi, risiko

\begin{abstract}
Mushroom is one of the leading vegetable commodities that are widely cultivated in Karawang Regency. The aims of this study were 1) to determine the risks faced by mushroom farmers and how the risks to production, prices and incomes 2) farmers' perceptions of risk in Cilamaya Kulon District, 3) how farmers faced risks. The method used is descriptive analytic. This research was conducted in Cilamaya Kulon sub-district which is spread across the villages of Pasirukem, Pasirjaya and Muktijaya. The data analysis used is descriptive analysis to describe the types of risk and how farmers face risk, quantitative analysis to measure production risk, price and opinion by using the coefficient of variation. and analysis of farmers' perceptions which were measured using a Likert scale. The results showed that the types of risks faced by mushroom farmers in Cilamaya Kulon District were: production risk, namely poor seed quality, price/market risk, namely fluctuating selling prices, institutional risk, namely no agricultural extension workers, human risk, namely reduced labor. work, the financial risk is the small amount of capital owned by farmers. Farmers have a good perception of risk because they think the risks that occur are not too disturbing. Farmers' ways of dealing with risk are: Before farmers start farming, farmers make plans with farmer groups. During the production period, farmers adjust the temperature in the
\end{abstract}




\section{ANALISIS RISIKO USAHATANI JAMUR MERANG \\ DI KECAMATAN CILAMAYA KULON KABUPATEN KARAWANG \\ Kiki Sasmita, Abubakar, Luthfi Nur'azkiya}

mushroom kumbung so that the temperature is maintained. After experiencing the risk, farmers continue to farm mushroom and look for other jobs to get additional income.

Keywords : perception, risk, straw mushroom

\section{PENDAHULUAN}

Sektor pertanian merupakan sektor yang sangat penting, baik dalam jangka panjang pembangunan ekonomi maupun untuk pemulihan ekonomi jangka pendek. Peranan sektor pertanian adalah sebagai sumber penghasil bahan kebutuhan pokok termasuk makanan pokok, sandang dan papan, menyediakan lapangan kerja bagi sebagian besar penduduk, memberikan sumbangan terhadap pendapatan nasional yang tinggi, dan memberikan devisa bagi negara.(Astuti,2017).

Saat ini kondisi di sektor pertanian mengalami peningkatan, menurut Dahiri dan Fitri (2020), kinerja sektor pertanian menunjukkan keadaan yang berkebalikan dengan sektor lainnya. Sektor pertanian merupakan satu-satunya sektor yang berhasil tumbuh positif diatas 6 persen pada kuartal 1-2020, sehingga menjadi penyangga pertumbuhan ekonomi nasional, salah satunya yaitu sektor hortikultura.

Menurut Badan Pusat Statistik dan Direktorat Jendral Hortikultura, produksi dan luas panen jamur nasional terus mengalami fluktuatif. Luas panen pada tahun 2015 seluas 536 ha, tahun 2016 seluas 467 ha, tahun 2017 seluas 475 ha, tahun 2018 seluas 440 ha, dan pada tahun 2019 seluas 462 ha. Sedangkan untuk data produksi nasional jamur juga mengalami fluktuatif. Produksi jamur pada tahun 2015 sebanyak 3,348,464 ton, sedangkan pada tahun 2016 menurun menjadi 4.914 ton, tahun 2018 produksi jamur sebanyak 37.020 ton sedangkan pada tahun 2018 produksi jamur sebanyak 31.052 ton, dan pada tahun 2019 produksi jamur merang sebanyak 33.163 ton. Ini menunjukkan bahwa prduktivitas jamur secara nasional terus mengalami fluktuatif.

Jamur merang (Volvariella volvacea) merupakan jamur yang paling dikenal, terutama untuk masyarakat Asia Tenggara, dan telah lama dibudidayakan sebagai bahan pangan, karena termasuk golongan jamur yang enak rasanya. Jamur merang banyak dibudidayakan di beberapa kota, salah satunya di Kabupaten Karawang yang tersebar di beberapa kecamatan yaitu kecamatan Jatisari, Banyusari, Cilamaya Wetan, Cilamaya Kulon, Lemahabang, Telaga Sari, Tirtajaya dan Rawamerta. Namun 
saat ini produktivitas jamur merang di Kecamatan Cilamaya Kulon terus mengalami penurunan. Berdasarkan data dari Dinas Pertanian Kabupaten Karawang produktivitas jamur merang dari tahun ke tahun terus mengalami penurunan. Pada tahun 2015 jumlah produksi jamur merang mencapai $1.120 .500 \mathrm{~kg}$ dengan luas lahan 265.000 $\mathrm{m}^{2}$. Sedangkan pada tahun 2016 produksi jamur merang menurun. Produksi jamur merang pada tahun 2016 hanya sebesar $724.200 \mathrm{~kg}$ dengan luas lahan $140.000 \mathrm{~m}^{2}$. Kemudian pada tahun 2017 produksi jamur merang kembali mengalami peningkatan menjadi $945.000 \mathrm{~kg}$ dengan luas lahan seluas $285.000 \mathrm{~m}^{2}$, dan pada tahun 2018 sapai 2019 produksi jamur merang masing-masing hanya sebesar $446.000 \mathrm{~kg}$ dengan luas lahan $166.000 \mathrm{~m}^{2}$ dan $425.000 \mathrm{~kg}$ dengan luas lahan $126.000 \mathrm{~m}^{2}$.

Produksi jamur merang terus mengalami penurunan, menurut para petani jamur merang di Kecamatan Cilamaya Kulon, faktor terbesar yang mempengaruhi produksi jamur merang yaitu kualitas bibit yang kurang baik, disamping itu kualitas pengomposan pada media tanam juga harus masak sehingga produksi jamur merang optimal.
Siswanti (2020) menjelaskan definisi risiko yaitu berhubungan dengan ketidakpastian, ini terjadi karena kurang atau tidak tersedianya informasi yang cukup tentang apa yang akan terjadi. Sesuatu yang tidak tersedianya (uncertain) dapat berakibat menguntungkan atau merugikan. Seluruh kegiatan yang dilakukan baik perorangan atau perusahaan mengandung risiko.

Harwoord at al dalam bukunya yang berjudul Managing Risk in Farming Concepts, Researh, and Analysis menjelaskan tentang beberapa risiko yang sering terjadi pada pertanian dan dapat menurunkan tingkat pendapatan petani, yaitu: risiko hasil produksi, risiko harga/pasar, risiko institusi, risiko keuangan dan risiko yang bersumber dari manusia.

Persepsi merupakan proses akhir dari pengamatan yang diawali oleh proses pengindraan, yaitu proses diterimanya stimulus oleh alat indra, kemudian individu ada perhatian, lalu diteruskan ke otak, dan baru kemudian individu menyadari tentang sesuatu. (Widiyastuti, 2016).

Penelitian ini bertujuan untuk mengetahui: 1) risiko yang dihadapi petani jamur merang di Cilamaya Kulon dan bagaimana risiko terhadap harga, 


\section{ANALISIS RISIKO USAHATANI JAMUR MERANG \\ DI KECAMATAN CILAMAYA KULON KABUPATEN KARAWANG \\ Kiki Sasmita, Abubakar, Luthfi Nur'azkiya}

produksi dan pendapatan petani. 2) mengetahui persepsi petani jamur merang terhadap risiko usahatani jamur merang di Kecamatan Cilamaya Kulon. 3) mengetahui cara petani dalam menghadapi risiko usahatani jamur merang di Kecamatan Cilamaya Kulon.

\section{METODE PENELITIAN}

Penelitian tentang risiko usahatani jamur merang ini dilaksanakan di Kecamatan Cilamaya Kulon Kabupaten Karawang yang tersebar di 3 desa, yaitu Desa Pasirukeum, Pasirjaya, dan Muktijaya. Pemilihan lokasi penelitian dilakukan secara purposif yaitu secara sengaja. Pemilihan lokasi ini berdasarkan pertimbangan bahwa lokasi tersebut merupakan sentral budidaya jamur merang. Penelitian dilakukan selama kurang lebih 3 bulan. Terhitung sejak peneliti melakukan survey dan pengamatan awal pada bulan Oktober 2020, dan dilanjutkan kembali pada bulan Januari hingga Pebruari 2021. Jenis penelitian ini adalah deskriptif analitik. Penelitian ini juga bersifat kuantitatif dimana dalam pembahasan terdapat perhitungan untuk mengukur tingkat risiko produksi, biaya dan pendapatan petani jamur merang yang ada di Kecamatan Cilamaya Kulon dengan menggunakan perhitungan koefisien variasi. Teknik pengambilan data dilakukan dengan cara observasi, wawancara dengan menggunakan kuesioner dan pencatatan hasil wawancara dengan jumlah responden sebanyak 30 orang petani yang ditentukan dengan quota sampling dengan pertimbangan bahwa di desa tersebut banyak yang melakukan usahatani jamur merang, usahatani milik sendiri dan bangunan kumbung jamur terbuat dari bambu. Metode analisis data yang digunakan yaitu:

\section{Uji Validitas}

Uji validitas merupakan pengujian yang digunakan untuk menguji valid atau tidaknya suatu pertanyaan yang terdapat pada kuesioner penelitian. Menurut Sugiyono (2011), uji validitas merupakan salah satu usaha penting yang harus dilakukan guna mengukur kevalidan dari instrumen. Syarat minimum suatu item pertanyaan dikatakan valid apabila hasilnya sebesar 0,30 atau lebih. Kriteria dalam menetukan validitas dalam suatu instrumen penelitian adalah sebagai berikut.

1. Apabila r-hitung > r-tabel maka pernyataan tersebut valid.

2. Apabila r-hitung < r-tabel maka pernyataan tersebut tidak valid. 


\section{Uji Reliabilitas}

Uji reliabilitas merupakan salah satu cara yang dapat dilakukan untuk menguji sejauh mana pengukuran memberikan hasil yang relatif stabil bila dilakukan pengukuran kembali. Pengujian ini dikatakan reliabel jika memberikan nilai Cronbach Alpha $>0,60$. (Tavakol dalam Ikasari 2016)

Analisis jenis-jenis risiko usahatani jamur merang di Kecamata Cilamaya Kulon

Jenis-jenis risiko usahatani jamur merang yang dihadapi oleh petani jamur merang di Kecamatan Cilamaya Kulon dapat diketahui dengan menggunakan analisis deskriptif, sedangkan untuk mengukur risiko terhadap biaya, produksi dan pendapatan dapat dihitung menggunakan perhitungan koefisien variasi. Menurut Wirawan (2016), koefisien variasi adalah perbandingan antara simpangan baku sekelompok data/pengamatan dengan rata-rata hitungannya (mean). perhitungan koefisien variasi dapat dihitung dengan menggunakan rumus sebagai berikut :

$\mathrm{CV}=\sigma / \mathrm{xr}$

Dimana :

CV : Koefisien Variasi

$\sigma \quad$ : Standar deviasi (simpangan baku)

$\mathrm{xr}$ : Nilai rata-rata
Menentukan hipotesis nol (Ho) dan hipotesis Alternatif (Ha)

Ho : Diduga risiko usahatani jamur merang yang dihadapi petani jamur merang di Kecamatan Cilamaya Kulon tinggi.

Ha : Diduga risiko usahatani jamur merang yang dihadapi petani jamur merang di Kecamatan Cilamaya Kulon rendah.

Dasar pengambilan keputusan:

Ho : $\mathrm{CV} \geq 1$

$\mathrm{Ha}: \mathrm{CV}<1$

Ho diterima dan Ha ditolak jika risiko usahatani jamur merang di Kecamatan Cilamaya Kulon tinggi dengan nilai $\mathrm{CV} \geq$ 1.

Ha diterima dan Ho ditolak jika risiko usahatani jamur merang di Kecamatan Cilamaya Kulon rendah dengan nilai CV $<1$

\section{Analisis persepsi petani terhadap risiko usahatani jamur merang}

Analisis persepsi petani terhadap risiko dapat diukur dengan menggunakan skala likert. Machali (2018) menyatakan bahwa skala likert digunakan untuk mengukur sikap, pendapat, persepsi seseorang tentang gejala atau masalah sosial yang dialami masyarakat. Beberapa bentuk jawaban pertanyaan atau pernyataan dari skala likert mempunyai 


\section{ANALISIS RISIKO USAHATANI JAMUR MERANG \\ DI KECAMATAN CILAMAYA KULON KABUPATEN KARAWANG \\ Kiki Sasmita, Abubakar, Luthfi Nur'azkiya}

gradasi (tingkatan) dari sangat positif sampai pada sangat negatif, yang dapat berupa kata-kata antara lain:

a) Sangat baik

b) Cukup baik

c) Tidak baik

Untuk total skor dari setiap pertanyaan yang diajukan menggunakan rumus sebagai berikut (Stiyawan, 2016):

Total Skor $=\mathrm{T} \times \mathrm{Pn}$

Dimana :

Total Skor $=$ Jumlah skor keseluruhan

$\mathrm{T}=$ Jumlah responden yang memilih $\mathrm{x}$ jumlah pertanyaan

$\mathrm{Pn}=$ Pilihan angka skor likert

Selanjutnya untuk mendapatkan hasil interpretasi, harus diketahui nilai skor tertinggi (Y) dan skor terendah (X) dengan rumus sebagai berikut:

$\mathrm{Y}=$ skor tertinggi likert $\mathrm{x}$ jumlah responden $\mathrm{x}$ jumlah pertanyaan

$\mathrm{X}=$ skor terendah likert $\mathrm{x}$ jumlah responden $\mathrm{x}$ jumlah pertanyaan

Nilai indeks skor $=$ Skor tertinggi $\mathrm{x} 100$

Selanjutnya untuk mengetahui letak nilai indeks terlebih dahulu harus menghitung interval (jarak) dengan rumus sebagai berikut :

$$
\begin{aligned}
\mathrm{I} & =100 / \mathrm{h} \\
& =100 / 3 \\
& =33,3
\end{aligned}
$$

Keterangan:
$\mathrm{I} \quad=$ Interval
$\mathrm{h} \quad=$ skor tertinggi likert

Sehingga interpretasi persepsi petani terhadap risiko usahtani jamur merang adalah sebagai berikut:

$0 \% \leq$ skor $<33,3 \%=$ Tidak baik

$33,3 \% \leq$ skor $<66,6 \%=$ Cukup baik

$66,6 \% \leq$ skor $\leq 100 \%=$ Baik

\section{Analisis cara petani dalam menhadapi risiko usahatani jamur merang}

Cara petani dalam menghadapi risiko usahatani jamur merang menggunakan analisis deskriptif. Metode deskriptif merupakan metode penelitian yang digunakan umtuk menggambarkan masalah yang terjadi pada masa sekarang atau yang sedang berlangsung. Analisis ini menggambarkan tentang cara yang dilakukan oleh petani padi dalam menghadapi risiko usahataninya.

\section{HASIL DAN PEMBAHASAN}

\section{A. Hasil pengujian instrumen Uji validitas}

Uji validitas merupakan pengujian yang digunakan untuk menguji valid atau tidaknya suatu pertanyaan yang terdapat pada kuesioner penelitian. Pengujian validitas pada instrumen penelitian ini dilakukan dengan menggunakan SPSS 
25. adapun hasil perhitungan uji validitas dapat dilihat pada Tabel 1.

Tabel 1 Uji validitas

\begin{tabular}{cccc}
\hline $\begin{array}{c}\text { No Item } \\
\text { Pertanyaan }\end{array}$ & $\mathrm{r}$ - hitung & $\mathrm{r}$ - tabel & Keterangan \\
\hline 1 & 0,378 & 0,30 & Valid \\
2 & 0,425 & 0,30 & Valid \\
3 & 0,437 & 0,30 & Valid \\
4 & 0,400 & 0,30 & Valid \\
5 & 0,616 & 0,30 & Valid \\
6 & 0,626 & 0,30 & Valid \\
7 & 0,397 & 0,30 & Valid \\
8 & 0,562 & 0,30 & Valid \\
9 & 0,432 & 0,30 & Valid \\
10 & 0,497 & 0,30 & Valid \\
\hline
\end{tabular}

Sumber : Pengolahan IBM Statistik 25

Berdasarkan Tabel 1 dapat diketahui bahwa dari 10 item pertanyaan dari kuesioner mengenai analisis risiko usahatani jamur merang dinyatakan valid karena r-hitung $>$ dari r-tabel sehingga semua item tersebut dapat digunakan pada saat penelitian.

\section{Uji reliabilitas}

Uji reliabilitas merupakan salah satu cara yang dapat dilakukan untuk menguji sejauh mana pengukuran memberikan hasil yang relatif stabil bila dilakukan pengukuran kembali. Pengujian reliabilitas pada instrumen penelitian ini dilakukan dengan menggunakan SPSS 25. Adapun hasil perhitungan uji validitas dapat dilihat pada Tabel 2.

Tabel 2 Uji reliabilitas

\begin{tabular}{cc}
\hline \multicolumn{2}{c}{ Reliability Statistics } \\
\hline \multicolumn{2}{c}{ Cronbach's Alpha }
\end{tabular}

Berdasarkan Tabel 2 hasil uji reliailitas analisis risiko usahatani jamur merang menunjukkan hasil cronbach alpha sebesar 0,617. hal tersebut dapat disimpulkan bahwa pertanyaan tersebut reliabel karena 0,617>0,60.

\section{B. HASIL ANALISIS DATA}

1. Risiko yang dihadapi petani jamur merang di Kecamatan Cilamaya Kulon dan kondisi risikonya

a. Jenis-jenis risiko usahatani jamur merang di Kecamatan Cilamaya Kulon Kabupaten Karawang

Risiko adalah kemungkinan terjadinya suatu peristiwa yang dapat dialami oleh petani dalam menjalankan usahatani, namun masih bisa dikendalikan. Jenis-jenis risiko yang dialami oleh para petani jamur merang di Kecamatan Cilamaya Kulon yaitu risiko yang bersumber dari produksi, risiko yang bersumber dari harga/pasar, risiko yang bersumber institusi, risiko yang bersumber dari manusia dan risiko yang bersumber dari keuangan. Adapun jeis-jenis risiko usahatani jamur merang di Kecamatan Cilamaya Kulon tedapat pada Tabel 3.

Berdasarkan Tabel 3 di atas risiko yang berumber dari produksi terjadi karena kualitas bibit yang kurang bagus. Hal tersebut terjadi karena pada saat penelitian petani kesulitan mendapatkan 
kualitas bibit yang bagus seingga hasil produksi petani berkurang. Risiko yang bersumber dari harga/pasar yaitu disebabkan karena harga jual fluktuatif hal ini terjadi karena pada saat proses produksi petani kesulitan mendapatkan kualitas bibit yang kualitas nya bagus sehingga harga jamur merang mengalami fluktuatif. Risiko yang bersumber dari institusi yaitu tidak adanya penyuluh pertanian, hal ini dikarenakan pada saat penelitian dilakukan banyak petani jamur merang yang sudah tidak melakukan usahatani jamur merang melainkan berpindah menjadi usahatani padi, sehingga penyuluh khususnya yang menangani jamur merang sudah tidak aktif dalam melakukan kegiatan penyuluhan. Risiko yang bersumber dari manusia yaitu berkurangnya tenaga kerja, hal ini terjadi karena para pemuda yang ada di desa tersebut enggan untuk melakukan usahatani jamur merang sehingga mereka lebih memilih bekerja di luar sektor pertanian dan risiko yang bersumber dari keuangan yaitu modal yang dimiliki petani sedikit sehingga para petani dalam melakukan usahatani jamur merang meminjam modal kepada bandar yang dapat berupa pinjaman uang maupun dapat berupa bibit dan alat-alat untuk melakukan usahatani jamur merang.

Tabel 3. jenis-jenis risiko usahatani jamur merang di Kecamatan Cilamaya Kulon

\begin{tabular}{|c|c|c|c|}
\hline No & Risiko & Sumber & Jumlah \\
\hline 1 & $\begin{array}{l}\text { Risiko } \\
\text { produksi }\end{array}$ & $\begin{array}{l}\text { Kualitas bibit } \\
\text { kurang bagus }\end{array}$ & 24 \\
\hline 2 & $\begin{array}{l}\text { Risiko } \\
\text { harga/pasar }\end{array}$ & $\begin{array}{l}\text { Harga jual } \\
\text { fluktuatif }\end{array}$ & 18 \\
\hline 3 & $\begin{array}{l}\text { Risiko } \\
\text { institusi }\end{array}$ & $\begin{array}{l}\text { Tidak ada } \\
\text { penyuluh } \\
\text { pertanian }\end{array}$ & 19 \\
\hline 4 & $\begin{array}{l}\text { Risiko } \\
\text { manusia }\end{array}$ & $\begin{array}{l}\text { Berkurangnya } \\
\text { tenaga kerja }\end{array}$ & 17 \\
\hline 5 & $\begin{array}{l}\text { Risiko } \\
\text { keuangan }\end{array}$ & $\begin{array}{l}\text { Modal yang } \\
\text { dimiliki sedikit }\end{array}$ & 24 \\
\hline
\end{tabular}

Sumber : Analisis data primer, 2021

\section{b. Kondisi risiko terhadap harga, produksi dan pendapatan dalam usahatani jamur merang di Kecamatan Cilamaya Kulon}

Perhitungan mengenai besarnya risiko produksi, risiko biaya dan risiko pendapatan usahatani jamur merang di Kecamatan Cilamaya Kulon Kabupaten Karawang dapat di analisis dengan menggunakan perhitungan koefisien variasi. Adapun perhitungan risiko dapat ditunjukkan pada Tabel 4.

Tabel 4 Besaran risiko biaya, produksi dan pendapatan pada usahatani jamur merang di Kecamatan Cilamaya Kulon

\begin{tabular}{clll}
\hline No & Risiko & $\begin{array}{c}\text { Nilai oefisien } \\
\text { Variasi }\end{array}$ & Kategori \\
\hline 1. & Biaya & 0,29 & Rendah \\
2. & Produksi & 0,015 & Rendah \\
3. & Pendapatan & 0,62 & Rendah \\
\hline
\end{tabular}

Sumber : Analisis data primer, 2021

Tabel 4 menjelaskan tentang tinggi rendahnya risiko yang dihadapi petani jamur merang di Kecamatan Cilamaya 
Kulon. Berdasarkan perhitungan analisis biaya terhadap risiko didapatkan hasil bahwa biaya memiliki tingkat risiko yang rendah yaitu sebesar 0,29. Hal tersebut dikarenakan biaya-biaya yang dikeluarkan untuk melakukan proses produksi jamur merang tergolong murah, seperti harga jerami, kapur, kapas dan bekatul. Produksi memiliki tingkat risiko yang rendah yaitu sebesar 0,0015. hal tersebut dikarenakan selama masa produksi bibit jamur merang yang digunakan kualitasnya kurang bagus, akan tetapi dapat menghasilkan jamur merang sehingga para petani tidak mengalami gagal panen. Pendapatan memiliki tingkat risiko yang rendah yaitu sebesar 0,62 hal tersebut dikarenakan walaupun dengan hasil produksi yang rendah para petani mampu memperoleh keuntungan. Nilai koefisien variasi biaya, produksi dan pendapatan mempunyai nilai rata-rata $\mathrm{KV}<1$ yang berarti $\mathrm{Ha}$ diterima dan Ho ditolak.

2. Persepsi Petani tentang risiko yang dihadapi dalam usahatani jamur merang di Kecamatan Cilamaya Kulon Kabupaten Karawang

\section{a. Persepsi petani tentang risiko dalam usahatani jamur merang}

Persepsi merupakan tanggapan atau pandangan tentang suatu fenomena atau hubungan. Dengan adanya persepsi petani mampu menyadari keadaan lingkungan sekitar dan juga tentang keadaan petani itu sendiri sehingga berdasarkan hasil penelitian mengenai persepsi petani jamur merang terhadap risiko menjelaskan bahwa petani mengganggap risiko adalah semua hal yang dapat menyebabkan kerugian pada usahatani jamur merang dengan jumlah petani sebanyak 17 orang atau sebesar $56,7 \%$. Usahatani jamur merang dikatakan gagal menurut persepsi petani jika produksi jamur merang yang dihasilkan relatif rendah dengan jumlah petani yang memilih sebanyak 22 orang atau sebesar 73,3\%. Tingkat risiko produktivitas usahatani jamur merang menurut persepsi petani adalah sedang dengan tingkat kegagalan panen 20-65\% sebanyak 19 orang atau sebesar $63,3 \%$.

\section{b. Baik buruknya persepsi petani terhadap risiko usahatani jamur merang}

Baik buruknya persepsi petani terhadap risiko usahatani jamur merang di Kecamatan Cilamaya Kulon dapat dianalisis dengan menggunakan perhitungan skala likert. Perhitungan skala likert dimulai pada saat perhitungan skor pertanyaan yang terdapat didalam kuesioner. Adapun hasil perhitungan skor pertanyaan pada kuesioner penelitian terdapat dapa Tabel 5. 
ANALISIS RISIKO USAHATANI JAMUR MERANG

DI KECAMATAN CILAMAYA KULON KABUPATEN KARAWANG

Kiki Sasmita, Abubakar, Luthfi Nur'azkiya

Tabel 5. Indikator baik buruknya persepsi petani terhadap risiko

\begin{tabular}{lccccccccccccc}
\hline \multicolumn{1}{c}{ Kategori } & \multicolumn{10}{c}{ Nilai Skor } & \multirow{2}{*}{ Total } \\
\cline { 2 - 12 } & 1 & 2 & 3 & 4 & 5 & 6 & 7 & 8 & 9 & 10 & \\
\hline Sangat berpengaruh & 66 & 24 & 18 & 18 & 6 & 15 & 18 & 42 & 69 & 24 & 300 \\
Cukup berpengaruh & 16 & 44 & 34 & 16 & 16 & 26 & 48 & 30 & 10 & 36 & 276 \\
Tidak berpengaruh & 0 & 0 & 7 & 16 & 20 & 12 & 0 & 1 & 2 & 4 & 62 \\
Jumlah & 82 & 68 & 59 & 50 & 42 & 53 & 66 & 73 & 81 & 64 & 638 \\
\hline
\end{tabular}

Sumber : Analisis data primer, 2021

Tabel 5 menunjukkan bahwa indeks skor persepsi petani terhadap usahatani jamur merang di Kecamatan Cilamaya Kulon Kabupaten Karawang sebesar $70,88 \%$.

Indeks tersebut menandakan bahwa persepsi petani terhadap risiko usahatani jamur merang adalah baik. Petani memiliki persepsi baik terhadap risiko usahatani jamur merang karena para petani beranggapan bahwa risiko tersebut tidak terlalu mengganggu usahatani jamur merang dan risiko tersebut masih bisa diatasi oleh para petani jamur merang yang ada di Kecamatan Cilamaya Kulon Kabupaten Karawang.

\section{Strategi petani dalam menghadapi risiko usahatani jamur merang di Kecamatan Cilamaya Kulon}

Strategi merupakan suatu cara yang digunakan para petani untuk menghadapi suatu masalah/risiko. Berdasarkan penelitian yang telah dilakukan petani jamur merang memiliki strategi untuk mengahadapi risiko yang tergolong menjadi 3 fase, yaitu bagaimana persepsi petani dalam menghadapi risiko usahatani jamur merang yang dimulai pada saat sebelum terjadi risiko atau dalam masa pra produksi, produksi dan setelah terjadi risiko. Sebelum mengalami risiko petani lebih dominan memilih untuk membuat perencanaan sebelum melakukan usahatani jamur merang bersama kelompok tani agar petani siap jika terjadi masalah/risiko yaitu dengan jumlah petani sebanyak 15 orang atau sebesar 50\%. Masa produksi merupakan segala kegiatan yang dilakukan untuk menciptakan hasil produksi yang baik maupun buruk, sehingga untuk mendapatkan hasil produksi yang berkualitas petani lebih memilih pengaturan suhu didalam kumbung jamur merang agar suhu tetap terjaga dengan jumlah petani yang memilih sebanyak 25 petani atau sebesar 83,33 \%. Setelah mengalami risiko sebagian petani lebih memilih tetap melanjutkan usahatani jamur merang, disamping itu juga mencari pekerjaan lain guna mendapatkan tambahan dengan jumlah petani yang memilih sebesar 15 orang atau sebesar $50 \%$. 


\section{KESIMPULAN DAN SARAN}

\section{Kesimpulan}

Berdasarkan hasil penelitian yang telah dilakukan dapat ditarik kesimpulan sebagai berikut:

1. Jenis-jenis risiko usahatani jamur merang yang dihadapi petani jamur merang di Kecamatan Cilamaya Kulon yaitu, risiko produksi adalah kualitas bibit yang kurang bagus, risiko harga/pasar adalah harga jual yang fluktuatif, risiko institusi adalah tidak ada penyuluh pertanian yang bertugas, risiko manusia adalah berkurangnya tenaga kerja, risiko keuangan adalah modal yang dimiliki oleh petani sedikit. analisis risiko tergolong rendah yaitu dengan nilai rata-rata $\mathrm{KV}<1$ yang berarti $\mathrm{Ha}$ diterima dan Ho ditolak.

2. Petani jamur merang memiliki persepsi yang baik terhadap risiko

3. Strategi petani dalam mengahadapi risiko adalah sebelum melakukan usahatani atau sebelum terjadi risiko, petani membuat perencanaan bersama kelompok tani agar petani siap jika terjadi masalah/risiko. Ssaat masa produksi para petani melakukan pengaturan suhu di dalam kumbung jamur merang agar suhu tetap terjaga. Setelah mengalami risiko, para petani tetap melanjutkan usahatani jamur merang, disamping itu juga mencari pekerjaan lain guna untuk mendapatkan pendapatan tambahan

\section{Saran}

1. Lembaga Pemerintahan Dinas Kabupaten Karawang harus lebih memperhatikan kondisi para petani jamur merang yang ada di Kecamatan Cilamaya Kulon, karena banyak petani yang merasa kesulitan karena tidak adanya lembaga penyuluh yang bertugas untuk membantu para petani jamur merang apabila sedang menghadapi kendala pada saat proses budidaya berjalan.

2. Unit Pelaksana Teknis Daerah (UPTD) Kecamatan Cilamaya Kulon harus lebih memperhatikan penyimpanan dokumen seperti data-data tetap tentang jumlah petani jamur merang yang ada di Kecamatan Cilamaya Kulon supaya pada saat dibutuhkan data tersebut sudah tersedia.

3. Bagi petani harus lebih aktif dalam mencari informasi tentang usahatani jamur merang supaya apabila terjadi masalah petani mampu memcahkan permasalahan tersebut sehingga pada saat panen tidak banyak hasil panen yang terbuang. 


\section{DAFTAR PUSTAKA}

Astuti, D.R.D. 2017. Ekonomika agribisnis (teori dan kasus). Universitas Negeri Makassar, Makassar.

Dahiri dan Fitri. 2020. Buletin APBN. Vol.V. Pusat Kajian Anggaran DPR-RI, Jakarta

Dinas Pertanian. 2015. Laporan tanam, panen dan produksi jamur Kabupaten Karawang Tahun 2015. Distan tanaman sayuran dan biofarmaka, Karawang . 2016. Laporan tanaman, panen dan produksi jamur Kabupaten Karawang Tahun 2016. Distan sayuran dan biofarmaka, Karawang . 2017. Laporan tanam, panen dan produksi jamur di Kabupaten Karawang Tahun 2017. Distan sayuran dan biofarmaka, Karawang . 2018. Laporan tanam, panen dan produksi jamur di Kabupaten Karawang Tahun 2018. Distan sayuran dan biofarmaka, Karawang . 2019. Laporan tanam, panen dan produksi jamur di Kabupaten Karawang tahun 2019. Distan sayuran dan biofarmaka, Karawang

Hardwood, J. at all . 1999. Managing risk in farming concepts, research, and analysis. Washington DC : Economic Research Service, USDA
Widiyastuti, W. 2016. Persepsi petani terhadap Pengembangan System Of Rice Intensification (SRI) di Kecamatan Moga Kabupaten Pemalang. Jurnal Agrista, 4(3): 20.

Siswanti,I dkk. 2020. Manajemen risiko perusahaan. Yayasan Kita Menulis, Medan

Sugiyono. 2011. Metode penelitian kuantitatif, kualitatif, dan R\&D. Bandung: Alfabeta

Ikasari, D.M. Deoranto, P. Silalahi, R.LR dan Citraresmi, A.D.P. Analisis faktor-faktor yang mempengaruhi perilaku konsumen dalam pengambilan keputusan pembelian beras organik. Jurnal teknologi pertanian, 17(1): 69-78.

Wirawan, N. 2016. Statistika ekonomi dan bisnis (Statistika Deskriptif). Keraras Emas, Denpasar.

Machali, I. Hidayat, A. 2018. The Handbook of Education Management: teori dan praktik pengelolaa sekolah/madrasah di Indonesia Edisi 2. jakarta. Kencana. Stiyawan, E. Jalil, F dan Effendy, E. 2016. Peran koperasi kopi terhadap produksi dan kesejahteraan petani kopi di Kecamatan Bandar Kapupaten Bener Meriah. Jurnal Agrifo, 1(1): 54-62 